Research Article

\title{
Reliability of ultrasonography in the diagnosis of acute appendicitis
}

\author{
Thomas George*, Rajan Babu K.N., Thomas P.T.
}

Department of General Surgery, Pushpagiri Institute of Medical Sciences, Tiruvalla, Kerala, India

Received: 25 November 2015

Revised: 29 November 2015

Accepted: 15 December 2015

\author{
*Correspondence: \\ Dr. Thomas George, \\ E-mail: tgeorge1956@yahoo.com
}

Copyright: () the author(s), publisher and licensee Medip Academy. This is an open-access article distributed under the terms of the Creative Commons Attribution Non-Commercial License, which permits unrestricted non-commercial use, distribution, and reproduction in any medium, provided the original work is properly cited.

\begin{abstract}
Background: Ultrasonography (US) is a commonly used investigation for diagnosing appendicitis. Although previous studies have shown US to be less sensitive than CT, proceeding with appendicectomy for all patients with positive US for appendicitis can save valuable time and cost. The aim of this study is to determine the value of a positive US for appendicitis and the outcome of operating on all these patients.

Methods: This is a retrospective analysis of a cohort of 200 consecutive patients who underwent appendicectomy due to a positive US diagnosis of appendicitis, between January 2014 and November 2015. Their histopathology reports were analysed to determine the number of patients with histological evidence of appendicitis.

Results: 179 out of the 200 patients showed a positive evidence of appendicitis on histology. This equates to a Positive Predictive Value (PPV) of $89.5 \%$ and a Negative Appendicectomy Rate (NAR) of $10.5 \%$ in these patients.

Conclusions: In our centre, we felt it was justified to operate on patients with a positive US for appendicitis due to a high PPV and low NAR. Furthermore, US have the added benefits of being less expensive, easy to do, repeatable and rapid to complete. Thus, we recommend that in centres such as ours where ultrasonography is available all the time, a positive US should be the first investigation of choice for deciding operative management. Patients with an equivocal US diagnosis should be monitored with further clinical assessment and CT scan.
\end{abstract}

Keywords: Ultrasonography, Appendicitis, Negative appendicectomy rate

\section{INTRODUCTION}

Appendicitis is the most common disease encountered in the emergency department requiring surgical intervention, with an $8.6 \%$ life time risk. ${ }^{1}$ Despite its prevalence, the diagnosis of appendicitis can be elusive and fraught with pitfalls because of the absence of pathognomonic signs or symptoms, the poor predictive value of associated laboratory testing and its varied clinical presentations. ${ }^{2,3}$ This leads to unnecessary laparotomies. Following significant advances in accuracy, imaging is an important part of modern work up of appendicitis, that remains a high risk disease for delayed or missed diagnosis in the emergency department. $^{4,5}$ Computed Tomography (CT) has been increasingly used to diagnose appendicitis in countries like the United States because of its high sensitivity and specificity. ${ }^{6}$ Accurate diagnosis is crucial to avoid unnecessary operations and complications of delayed diagnosis such as perforation and abscess formation. ${ }^{7}$ History and physical examination are highly variable and hence imaging has become standard before operation.

Use of ultrasonography for the diagnosis of appendicitis is growing. However, ultrasonography is highly operator dependent with a consequently wide reported sensitivity range $(44 \%-100 \%){ }^{8}$ Advantages of CT include less operator dependence, easier visualization of retrocaecal 
appendix, less interference of bowel gas, obesity or patient's pain and tenderness with good image quality. A major disadvantage of CT is the radiation exposure which is the major caveat and the single most important consideration in avoidance of the examination. ${ }^{6}$ Secondly cost is an impediment for the average Indian patient.

The graded compression technique in ultrasonography introduced by Puylaert in 1986 is apt to better visualize the inflamed appendix. ${ }^{9}$ Here the transducer is placed on the right lower quadrant and pressure is applied gradually while imaging, displacing overlying gas filled bowel loops. This non-invasive option is repeatable and is a cheap modality compared to CT. Ultrasound (US) findings indicative of appendicitis include a thickened wall, a non-compressible blind ending a peristaltic tubular structure, outer appendiceal diameter greater than $6 \mathrm{~mm}$, absence of gas in the lumen, appendicoliths, echogenic inflammatory periappendiceal wall change and increased blood flow to the appendiceal wall. ${ }^{9}$

The purpose of our study is to analyse the value of appendicectomy in all patients with a positive US of appendicitis irrespective of other clinical findings.

\section{METHODS}

This was a retrospective analysis of the medical records of 200 consecutive patients aged 13-72 who had been hospitalized through our emergency department during the period from January 2014 to November 2015 with a diagnosis of appendicitis by US. 142 patients had US scan carried out in the Emergency department mostly by senior resident radiologists. The rest of the patients came with a scan done elsewhere outside the hospital. The radiologists who performed the scan ranged from senior residents to highly experienced consultants. In our analysis an ultrasound scan that was able to visualize the appendix and show features of acute inflammation was recorded as a positive scan. All these patients were posted for emergency operation.

The histopathology of the resected specimen was reported by the consultant pathologist of our institution. Histological features of acute inflammation within the appendiceal parenchyma and faecoliths inside the lumen were deemed to be positive report for appendicitis, whereas anything else such as serosal congestion or lymphoid hyperplasia was considered to be a negative report for appendicitis.

\section{RESULTS}

Appendicitis was confirmed by histology in 179 patients out of the 200 operated. 8 patients did not have any evidence of appendicitis. 13 patients had only lymphoid hyperplasia with no evidence of acute inflammation (Table 1).
This gives a positive predictive value (PPV) of $89.5 \%$ and a Negative Appendicectomy Rate (NAR) of $10.5 \%$ in patients with a positive US for appendicitis.

Table 1: Histopathological diagnosis.

\begin{tabular}{|ll|}
\hline Histology & No. of cases \\
\hline Positive cases of appendicitis & \\
\hline Acute appendicitis & 154 \\
\hline Periappendicular abscess/ perforation & 14 \\
\hline Gangrenous appendicitis & 5 \\
\hline Obliterative appendicitis & 3 \\
\hline Faecolith in appendix & 3 \\
\hline Negative cases of appendicitis & \\
\hline Lymphoid hyperplasia & 13 \\
\hline Serosal congestion / Normal appendix & 8 \\
\hline
\end{tabular}

\section{DISCUSSION}

The definition of a negative appendicectomy that is most often used in the surgical literature is that which involves a normal appendix or is a medically unnecessary appendicectomy. ${ }^{10}$ This definition was adopted for our analysis to allow for meaningful comparison with the surgical literature.

Traditionally, a high NAR has been considered acceptable to minimize the number of missed cases of appendicitis, even up to $20-30 \%$ before the advent of CT. ${ }^{11,12}$ CT scan has $94 \%$ sensitivity and $95 \%$ specificity in diagnosing appendicitis. ${ }^{13}$ Hence CT abdomen is favored over US in many centre, particularly in the West. The overall sensitivity, specificity and PPV of US in adult and adolescent patients in various published series have been $86 \%, 81 \%$ and $84 \%$ respectively. ${ }^{8}$

In our study conducted over a 22-month period, we found US to be reliable when positive for appendicitis, as the PPV was $89.5 \%$ and the NAR after operation was $10.5 \%$. This may be attributed to better training of radiologists, as well as the recent improvements in ultrasonography imaging techniques and newer US machines. We believe at this level of accuracy it is justifiable to operate on all patients with a positive diagnosis of appendicitis by ultrasonography. Some of the pertinent benefits of US include that it is a relatively inexpensive modality and a simple and fast procedure to perform. Particularly in the setting of an acute abdomen, time is a valuable commodity and a rapid US scan would help reduce the development of complications such as perforation and peritonitis. $^{7}$ Furthermore, unlike CT there will be no undesirable exposure to radiation. CT is also expensive, often time consuming and competent reporting may not be available all the time. Given these findings, we recommend that in centers like ours where US is readily available and fairly accurate at identifying appendicitis, it should be the investigation of choice for determining operative treatment. However, in equivocal cases where ultrasonography does not provide a clear diagnosis, we 
recommend careful clinical observation and the use of CT for further management.

\section{Limitations}

Our study is limited by its retrospective, observational nature. We included only patients who had a positive US for appendicitis in our study. We have not included patients who had a negative US for the condition. Therefore, the negative predictive value, sensitivity and specificity of US in appendicitis were not evaluated. However, our aim was to highlight the value of a positive US for appendicitis in decision making for appendicectomy. Furthermore, earlier studies have shown that sonography has a high negative predictive value of $95 \%$ for appendicitis. ${ }^{14}$

\section{CONCLUSION}

In our centre, US examination has proven to be a valuable diagnostic tool when positive for appendicitis due to the high PPV of $89.5 \%$ and low NAR of $10.5 \%$. These patients should be operated on immediately to avoid the development of complications. Nevertheless, careful clinical monitoring and CT should be performed in cases where the diagnosis is ambiguous.

Funding: No funding sources Conflict of interest: None declared

Ethical approval: The study was approved by the institutional ethics committee

\section{REFERENCES}

1. Addiss DG, Shaffer N, Fowler BS, Tauxe RV. The epidemiology of appendicitis and appendectomy in the United States. Am. J. Epidemiol. 1990;132:91025.

2. Pittman-Waller VA, Myers J G, Stewart R M, Dent D L, Page C P, Gray GA et al. Appendicitis: Why so complicated? Analysis of 5755 consecutive appendectomies. Am Surg. 2000;66:548-54.

3. Vissers RJ, Lennarz WB. Pitfalls in appendicitis. Emerg Med Clin. North Am. 2010;28:103-18.

4. Reginelli A, Mandato Y, Solazzo A, Berritto D, Iacobellis F,Grassi R. Errors in the radiological evaluation of the alimentary tract: part II. Semin. Ultrasound CT MR. 2012;33:308-17.
5. Stabile IAA, Lorusso F, Niccoli AA, Di Maggio P, Fonio P, Losco $\mathrm{M}$ et al. Multidetector CT for the assessment of the groin region. Recenti Prog Med. 2012;103:483-8.

6. Hernanz-Schulman M. CT and US in the diagnosis of appendicitis: an argument for CT. Radiology 2010;255:3-7.

7. Papandria D, Goldstein SD, Rhee D, Salazar J H: Risk of perforation increases with delay in recognition and surgery for acute appendicitis. J Surg Res. 2013;184:723-9.

8. Pinto F, Pinto A, Russo A, Coppolino F, Bracale R, Fonio $\mathrm{P}$ et al. Accuracy of ultrasonography in the diagnosis of acute appendicitis in adult patients: review of the literature. Crit Ultrasound J. 2013;5 (Suppl 1):1-3.

9. Puylaert JB. Acute appendicitis: US evaluation using graded compression. Radiology. 1986;158: 355-60.

10. Webb EM, Nguyen A, Wang ZJ, Stengel JW, Westphalen AC, Coakley FV et al. The negative appendectomy rate: who benefits from preoperative CT? Am J Roentgenol. 2011;197:861-6.

11. Van Randen A, Bipat S, Zwinderman AH, Ubbink DT, Stoker J, Boermeester MA. Acute appendicitis: meta-analysis of diagnostic performance of CT and graded compression US related to prevalence of disease. Radiology .2008;249(1):97-106.

12. Suen K, Hayes IP, Thomson BNJ, Shedda S. Effect of the introduction of an emergency general surgery service on outcomes from appendicectomy. $\mathrm{Br} \mathbf{J}$ Surg. 2014;101:e141-6.

13. Terasawa T, Blackmore CC, Bent S, Kohlwes RJ. Systematic review: computed tomography and ultrasonography to detect acute appendicitis in adults and adolescents. Ann Intern Med. 2004;141: 537-46.

14. Pacharn P, Ying J, Linam LE, Brody AS, Babcock DS. Sonography in the evaluation of acute appendicitis: Are negative sonographic findings good enough? J Ultrasound Med.2010; 29:1749-55.

Cite this article as: George T, Babu RKN, Thomas PT. Reliability of ultrasonography in the diagnosis of acute appendicitis. Int Surg J 2016;3:59-61. 